OPEN ACCESS

Edited by:

Pier Giorgio Mastroberardino, Erasmus University Rotterdam,

Netherlands

Reviewed by:

Philip Forsyth Copenhaver,

Oregon Health \& Science University,

United States

Silvia Cerri,

"C. Mondino" National Neurological

Institute, Italy

*Correspondence:

Nicolas Sergeant

nicolas.sergeant@inserm.fr

Valérie Vingtdeux

valerie.vingtdeux@inserm.fr

${ }^{\dagger}$ These authors have contributed equally to this work

Received: 05 July 2018 Accepted: 02 November 2018 Published: 22 November 2018

Citation:

Evrard C, Kienlen-Campard P, Coevoet M, Opsomer R, Tasiaux B, Melnyk P, Octave J-N, Buée L, Sergeant $N$ and Vingtdeux $V$ (2018) Contribution of the

Endosomal-Lysosomal and Proteasomal Systems in Amyloid- $\beta$ Precursor Protein Derived Fragments Processing. Front. Cell. Neurosci. 12:435. doi: 10.3389/fncel.2018.00435

\section{Contribution of the} Endosomal-Lysosomal and Proteasomal Systems in Amyloid- $\beta$ Precursor Protein Derived Fragments Processing

\author{
Caroline Evrard ${ }^{1}$, Pascal Kienlen-Campard ${ }^{2}$, Mathilde Coevoet ${ }^{1}$, Rémi Opsomer', \\ Bernadette Tasiaux ${ }^{2}$, Patricia Melnyk ${ }^{1}$, Jean-Noël Octave², Luc Buée ${ }^{1}$, \\ Nicolas Sergeant ${ }^{1 * t}$ and Valérie Vingtdeux ${ }^{1 *+}$

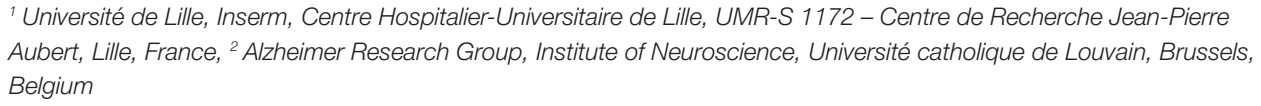

$A \beta$ peptides, the major components of Alzheimer's disease (AD) amyloid deposits, are released following sequential cleavages by secretases of its precursor named the amyloid precursor protein (APP). In addition to secretases, degradation pathways, in particular the endosomal/lysosomal and proteasomal systems have been reported to contribute to APP processing. However, the respective role of each of these pathways toward APP metabolism remains to be established. To address this, we used HEK 293 cells and primary neurons expressing full-length wild type APP or the $\beta$-secretasederived C99 fragment ( $\beta$-CTF) in which degradation pathways were selectively blocked using pharmacological drugs. APP metabolites, including carboxy-terminal fragments (CTFs), soluble APP (SAPP) and A $\beta$ peptides were studied. In this report, we show that APP-CTFs produced from endogenous or overexpressed full-length APP are mainly processed by $\gamma$-secretase and the endosomal/lysosomal pathway, while in sharp contrast, overexpressed C99 is mainly degraded by the proteasome and to a lesser extent by $\gamma$-secretase.

Keywords: Alzheimer's disease, amyloid precursor protein, amyloid beta peptide, APP-CTF, C99

\section{INTRODUCTION}

Amyloid deposits, that mainly consist of the extracellular aggregation of amyloid $\beta$-peptides $(A \beta)$ into plaques, are one of the major pathological hallmarks of Alzheimer's disease (AD) and the main targets of current clinical trials (Hung and $\mathrm{Fu}, 2017$ ). $\mathrm{A} \beta$ peptides are generated by sequential and compartmentalized cleavages of the type I transmembrane protein named Amyloid Precursor Protein (APP). Proteolytic cleavage of APP by $\beta$-secretase (mainly BACE1), characterized as the first step of the amyloidogenic pathway, releases APP carboxy-terminal fragments (APP-CTFs) named $\beta$-CTF or C99 that remain membrane bound and the soluble sAPP $\beta$ fragments that are secreted. 
$\beta$-CTFs are then processed within their transmembrane domain by $\gamma$-secretase, a transmembrane proteolytic complex, thereby releasing $\mathrm{A} \beta$ peptides and APP Intracellular Domain (AICD) (for a review see Wang et al., 2017). Alternatively to this amyloidogenic pathway, APP can be processed by an $\alpha$-secretase activity (Vingtdeux and Marambaud, 2012), which cleaves within the $A \beta$ sequence thus precluding its production. This $\alpha$-secretase cleavage of APP releases soluble sAPP $\alpha$ fragments that are secreted and membrane-bound APP-CTFs named $\alpha$-CTFs or C83, that can be further processed by $\gamma$-secretase (Figure 1A). Recently, the identification of new secretases, like $\delta$-secretase (asparagine endopeptidase), $\eta$-secretase (MT5-MMP) and meprin $\beta$, have added to the complexity of APP processing (Andrew et al., 2016). Meprin $\beta$ can be considered as an alternate $\beta$-secretase enzyme since it gives rise to a $\beta$-CTF starting at position 2 (Bien et al., 2012; Becker-Pauly and Pietrzik, 2017). $\delta$ -secretase and $\eta$-secretase generate larger APP-CTFs that can be further processed by $\alpha$ - or $\beta$ - and $\gamma$-secretases (Willem et al., 2015; Zhang et al., 2015; Baranger et al., 2016b; Figure 1B). Finally, it is also important to note that these secretases are active at various intracellular locations. While their exact location is still debated, we propose a schematic representation of their spatial location for APP cleavage in agreement with the literature (Figure 1C).

Among all the fragments generated along APP processing, $\beta$-CTFs are of particular interest since they are the direct precursors of $A \beta$ peptides. In addition, $\beta$-CTFs have been shown to accumulate before $A \beta$ peptides in vivo, and suggested to be instrumental in the initiation of the neurodegenerative process and cognitive alterations (Lauritzen et al., 2012). Inhibition of $\beta$-secretase cleavage of APP rescues long-term potentiation (LTP) and memory deficits in a mouse model of AD (Tamayev et al., 2012). Of note, $\beta$-CTFs accumulation was also described to occur in AD brains (Pera et al., 2013). While the exact impact of $\beta$-CTFs accumulation in $\mathrm{AD}$ is not completely elucidated yet, a better understanding of the mechanisms involved in APP-CTFs, and in particular $\beta$-CTFs, degradation is needed.

Indeed, alternatively to their cleavage by $\gamma$-secretase, lysosomal proteases and/or the proteasome are involved in APPCTFs degradation. APP has an internalization carboxy-terminal NPxY motif and is thus found along endosomal/lysosomal compartments (Morel et al., 2013; Tam et al., 2016; Xu et al., 2017). Inhibition of lysosomal proteases induces an accumulation of APP-CTFs (Vingtdeux et al., 2007a,b; González et al., 2017), showing that the endosome/lysosome pathway is important for the processing of APP. Other reports suggested that APP-CTFs, in particular $\beta$-CTFs, were rather processed by the proteasome (Skovronsky et al., 2000; Nunan et al., 2001, 2003). Additionally, the proteasome was also suggested to indirectly modulate APP metabolism by regulating the degradation of proteases implicated in APP metabolism (Marambaud et al., 1997; Flood et al., 2005).

Although $\gamma$-secretase, proteasome and lysosomal proteases were shown to be involved in APP processing and $\beta$-CTFs degradation, their mutual implication remains to be established. In the present study, we compared the contribution of these three degradation pathways on APP processing in HEK cells and in primary neuronal cultures expressing either full-length APPWT or the C99 fragment by using selective pharmacological drugs (Dyrks et al., 1992b).

\section{MATERIALS AND METHODS}

\section{HEK Cell Culture and Primary Neuronal Cell Culture}

HEK293 stably expressing or not full-length $\mathrm{APP}^{\mathrm{WT}}$ or C99 were previously described (Lefranc-Jullien et al., 2005) and kindly provided by Prof. F. Checler. Briefly, HEK cells were grown in Dulbecco's Modified Eagle Medium (DMEM, high glucose, pyruvate - GIBCO by Life Technologies) supplemented with $10 \%$ fetal bovine serum, $2 \mathrm{mM}$ L-glutamine, $1 \mathrm{mM}$ non-essential amino-acids and penicillin/streptomycin (GIBCO by Life Technologies) in a $5 \% \mathrm{CO}_{2}$ humidified incubator at $37^{\circ} \mathrm{C}$. Primary cultures of rat embryonic cortical neurons were prepared as previously described. After 6 days of culture, neurons were infected with recombinant adenovirus expressing either $\mathrm{APP}^{\mathrm{WT}}$ (corresponding to wild-type APP695 isoform) or C99 as described (Kienlen-Campard et al., 2002; Pitsi et al., 2002). All animal procedures used in the study were carried out in accordance with institutional and European guidelines and experimental protocols were approved by the Animal Ethics Committee from the Université catholique de Louvain (UCL, Brussels, Belgium).

\section{Drug Treatments}

Bafilomycin A1 ( $\left.\mathrm{Baf}_{\mathrm{Al}}\right)$ and Compound $\mathrm{E}$ (CompE) were purchased from Merck Millipore. Chloroquine (CQ), Lactacystin (Lacta) and MG132 were purchased from Sigma-Aldrich. Epoxomicin (Epoxo) was purchased from Abcam. Cells were plated into 6-well plates at a density of 500,000 cells per well, $24 \mathrm{~h}$ (h) before drug exposure. Cultures were briefly washed once with warm phosphate-buffered saline (PBS) and then exposed for 6 or $24 \mathrm{~h}$ to drug-treatments at the indicated concentrations. For primary cultures, treatments were performed at day 4 post-infection. At the end of treatments, the conditioned medium was collected and kept at $-80^{\circ} \mathrm{C}$ until use to evaluate the levels of $\mathrm{A} \beta_{1-40}, \mathrm{~A} \beta_{1-42}$ peptides and sAPP $\alpha /$ sAPP $\beta$ secretion by ELISA and electrochemiluminescence immunoassay, respectively. Then, cells were rinsed once with PBS and collected in $100 \mu \mathrm{L}$ of Laemmli buffer (10 mM Tris, 20\% glycerol and 2\% Sodium dodecyl sulfate) using a cell-scraper. The lysate was sonicated for $5 \mathrm{~min}$ before measurement of total protein concentration using the Pierce BCA Protein Assay Kit (Thermo scientific) according to the manufacturer's protocol. Samples were conserved at $-80^{\circ} \mathrm{C}$ before analysis.

\section{Subcellular Fractionation}

HEK293 stably expressing or not full-length APPWT or C99 were retrieved into $1 \mathrm{~mL}$ of a buffer composed of $10 \mathrm{mM}$ Tris- $\mathrm{HCl}$, $\mathrm{pH}=7.5 ; 0.25 \mathrm{M}$ sucrose; $1 \mathrm{mM}$ EDTA, $1 \times$ complete protease inhibitor cocktail and then, passed through a 26 gauge needle 10 times. Obtained lysates were centrifuged at $500 \mathrm{~g}$ for $10 \mathrm{~min}$ and 

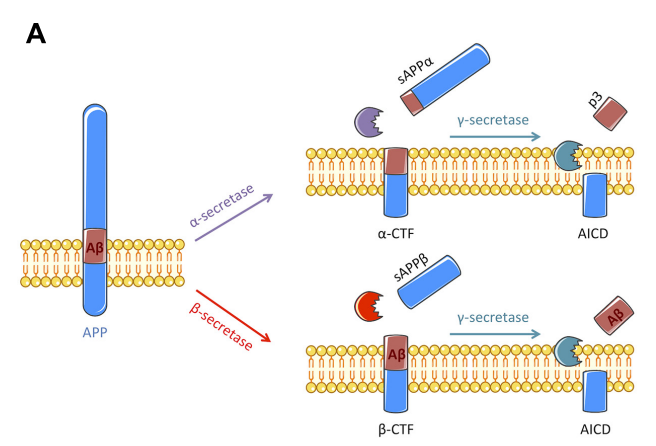

B
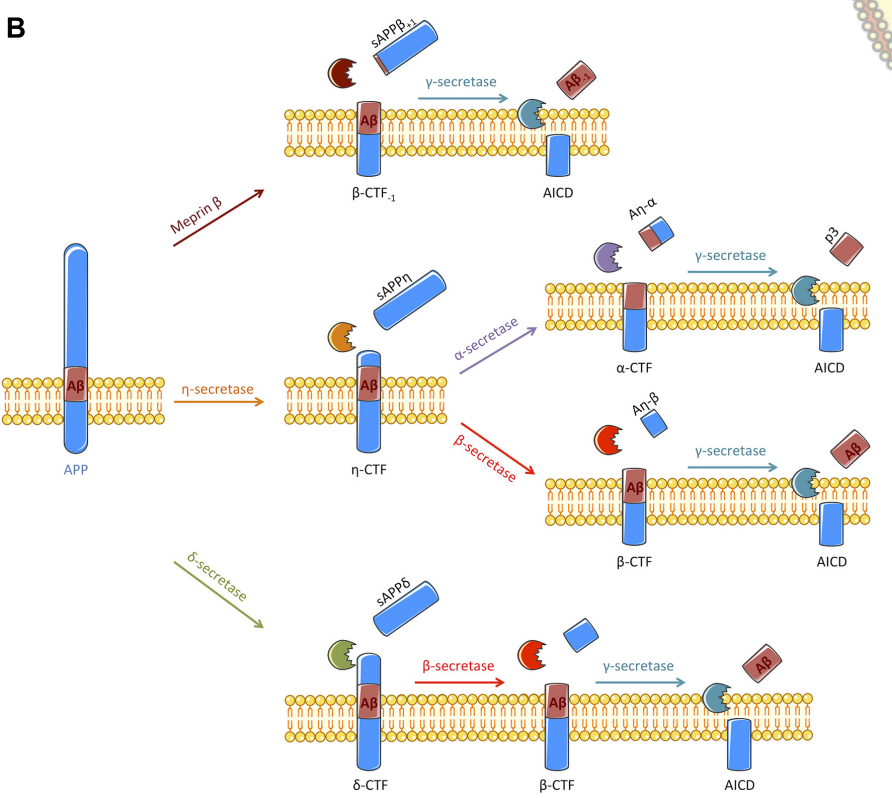

C
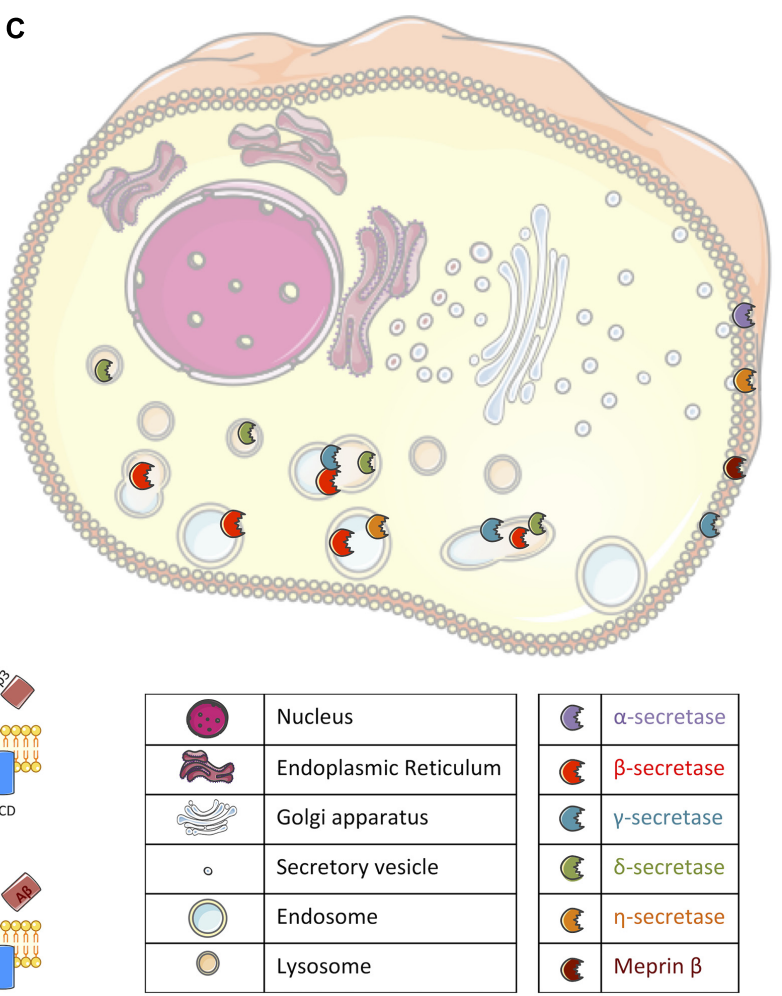

FIGURE 1 | Schematic representation of APP processing and the cellular localization of the different secretases involved. (A) Following synthesis and maturation, the amyloid precursor protein (APP) can classically follow two different pathways: the non-amyloidogenic or the amyloidogenic pathways, the latest being at the origin of A $\beta$ peptides production. In the non-amyloidogenic pathway, APP is first cleaved by $\alpha$-secretase (mallow) within the A $\beta$ sequence, liberating a soluble fragment sAPP $\alpha$ and a transmembrane carboxy-terminal fragment (APP-CTF) called $\alpha$-CTF. Then, $\gamma$-secretase (turquoise) processes $\alpha$-CTF into p3 and APP intracellular domain (AICD). In the amyloidogenic pathway, SAPP $\beta$ and $\beta$-CTF are released following APP cleavage by $\beta$-secretase (red). $\beta$-CTF is further processed by $\gamma$-secretase into $A \beta$ peptide and AICD. (B) Alternatively to a direct cleavage by $\alpha$ - or $\beta$-secretase, APP can be processed by other secretases that have been recently described. Meprin $\beta$ (brown) can act as an alternative $\beta$-secretase releasing SAPP $\beta$ with 1 amino acid longer and $\beta$-CTF with an amino acid less. $\beta$-CTF -1 is similarly cleaved by $\gamma$-secretase. $\eta$-secretase (orange) cleaves APP into SAPP $\eta$ and $\eta$-CTF. $\eta$-CTF can follow either the amyloidogenic or the non-amyloidogenic pathway, releasing A $\eta$ - $\beta$ and $\beta$-CTF or A $\eta-\alpha$ and $\alpha$-CTF, respectively. The remaining CTFs ( $\alpha$ - and $\beta$-) are likely processed by $\gamma$-secretase. $\delta$-secretase (green) processes APP into sAPP $\delta$ and $\delta$-CTF. Cleavage of $\delta$-CTF by $\beta$ - and $\gamma$-secretase releases A $\beta$ and AICD. (C) All these secretases are active in different cellular compartments. Thus, we propose a schematic representation of their spatial location for APP cleavage in agreement with the literature. $\alpha$-secretase and meprin $\beta$ were described to cleave APP at the cell surface where $\alpha$-CTF and $\beta$-CTF -1 can then be processed by $\gamma$-secretase (Lichtenthaler, 2011; Jäckle et al., 2015; Wang et al., 2017). $\gamma$-secretase cleavage was reported to occur at the plasma membrane and in endosomes (Kaether et al., 2006). $\beta$-secretase processing of APP is reported to occur in endosomal/lysosomal acidic compartments as it is the case for the $\delta$-secretase (Vassar et al., 1999; Zhang et al., 2015) where APP-CTFs could also be cleaved by $\gamma$-secretase. The location of APP processing by $\eta$-secretase is still unclear but it is likely that $\eta$-secretase is located the plasma membrane and also improves APP localization to endosomes (Baranger et al., 2016a, 2017). Figure was produced in part using Servier Medical Art.

pellets were discarded. Protein concentration was determined using the Pierce BCA Protein Assay Kit (Thermo scientific) according to the manufacturer's protocol. Supernatants were adjusted to $1.5 \mu \mathrm{g} / \mu \mathrm{L}$ and an aliquot (before ultra-centrifugation) was kept as the total protein fraction. Then, supernatants were centrifuged at $120,000 \mathrm{~g}$ for $45 \mathrm{~min}$ at $4^{\circ} \mathrm{C}$ to separate cytosolic (supernatants) and membrane fractions (pellets). Membrane fractions were resuspended in $250 \mu \mathrm{L}$ of NuPage NuPAGE ${ }^{\circledR}$ lithium dodecyl sulfate (LDS) 2X sample buffer supplemented with $20 \% \mathrm{NuPAGE}^{\circledR}$ sample reducing agents (Invitrogen). Total fraction, cytosolic and membrane fractions were analyzed by western blot.

\section{Western Blotting}

Cell protein samples were prepared for western-blot analysis by adding 1 volume of NuPage NuPAGE ${ }^{\circledR}$ LDS $2 \mathrm{X}$ sample buffer supplemented with $20 \% \mathrm{NuPAGE}^{\circledR}$ sample reducing agents (Invitrogen). Samples were heated $10 \mathrm{~min}$ at $100^{\circ} \mathrm{C} .10 \mu \mathrm{g}$ of total 
proteins per well were loaded onto precast $4-12 \%$ Criterion XT Bis-Tris polyacrylamide gels (Bio-Rad) and electrophoresis was achieved by applying a tension of $150 \mathrm{~V}$ during $90 \mathrm{~min}$ using a Criterion electrophoresis Cell with the NuPAGE ${ }^{\circledR}$ MOPS SDS running buffer (1X). Proteins were transferred to a nitrocellulose membrane of $0.4 \mu \mathrm{M}$ pore size (G\&E Healthcare) using the Criterion blotting system by applying a tension of $100 \mathrm{~V}$ for $45 \mathrm{~min}$. To resolve proteins of low molecular weights such as CTFs of APP, equal quantities of total proteins $(20 \mu \mathrm{g} /$ lane $)$ were loaded on $16 \%$ Tris-tricine polyacrylamide gels. Tris-tricine SDS-polyacrylamide gel electrophoresis and Western-blotting were performed as previously described (Vingtdeux et al., 2005). Molecular weights calibration was achieved using molecular weight markers (Novex and Magic Marks, Life Technologies). Protein transfer and quality were determined by a reversible Ponceau Red coloration (0.2\% Xylidine Ponceau Red and 3\% Trichloroacetic acid). Membranes were then blocked in $25 \mathrm{mM}$ Tris-HCl pH 8.0, $150 \mathrm{mM} \mathrm{NaCl}, 0.1 \%$ Tween-20 (v/v) (TBS$\mathrm{T})$ and $5 \%(\mathrm{w} / \mathrm{v})$ of skimmed milk (TBS-M) or $5 \%(\mathrm{w} / \mathrm{v})$ of bovine serum albumin (TBS-BSA) depending on the antibody during $1 \mathrm{~h}$. Membranes were rinsed three-times $10 \mathrm{~min}$ in TBS-T before incubation with primary antibodies overnight at $4^{\circ} \mathrm{C}$. Membranes were rinsed 3 times $10 \mathrm{~min}$ with TBS-T and then incubated with secondary antibodies for $45 \mathrm{~min}$ at room temperature (RT). The immunoreactive complexes were revealed using the $\mathrm{ECL}^{\mathrm{TM}}$ Western Blotting Detection Reagents (G\&E Healthcare) and a standard ECL detection procedure was then performed. Quantifications of protein expression levels were performed with ImageJ Software (NIH).

\section{Antibodies}

APP and APP-CTFs were detected with a rabbit APP-CterC17 antibody $(1 / 5,000)$ that was raised against the last 17 amino acids of the human APP sequence (Sergeant et al., 2002; Vingtdeux et al., 2005). $\beta$-CTFs were detected using an antiamyloid $\beta$ antibody clone W02 $(1 / 2,000)$ obtained from Merck Millipore. Anti-LC3B (1/2,000) and anti-p62/SQSTM1 $(1 / 1,000)$ were purchased from Cell Signaling Technology. Anti-mono and polyubiquitinylated conjugates $(1 / 1,000)$ was purchased from Enzo Life Sciences. Anti-N-cadherin $(1 / 1,000)$ was purschased from BD Biosciences. Anti- $\beta$-actin antibody $(1 / 10,000)$, antiGAPDH $(1 / 50,000)$, anti- $\beta$-tubulin $(1 / 1,000)$ and all secondary antibodies coupled with horseradish peroxidase were purchased from Sigma-Aldrich.

\section{A $\beta$ Peptides Quantification}

Collected medium was spun at $200 \mathrm{~g}$ for $5 \mathrm{~min}$ to eliminate cell debris. Secreted $A \beta_{1-40}$ and $A \beta_{1-42}$ peptides concentrations in $\mathrm{pg} / \mathrm{mL}$ were determined using amyloid beta 40 and 42 Human ELISA kits (Invitrogen) according to the manufacturer's instructions.

\section{sAPP $\alpha /$ sAPP $\beta$ Quantification}

Conditioned medium collected at the end of experiments was briefly centrifuged as describe above to eliminated cells debris. $\operatorname{sAPP} \alpha$ and $\operatorname{sAPP} \beta$ concentrations were determined using the
sAPP $\alpha /$ sAPP $\beta$ multiplex kit (Meso Scale Diagnostics, $\mathrm{MSD}^{\circledR}$ ) according to the manufacturer's instructions.

\section{Statistical Analysis}

The number of experiments for each experimental condition is indicated in the figure legends. Statistical analyses were performed with GraphPad Prism 6 program (GraphPad Software) by using the unpaired Student's test for pairwise comparisons and One way ANOVA with Bonferroni's multiple comparisons test for multiple pairwise comparisons. Statistical significance was set at ${ }^{*} p<0.05,{ }^{* *} p<0.01,{ }^{* * *} p<0.001$, and $* * * * p<0.0001$. All data are reported as mean \pm standard error of the mean (SEM) of at least $n=3$ experiments.

\section{RESULTS}

\section{APP-Derived Carboxy-Terminal Fragments Are Mainly Processed by $\gamma$-Secretase and Lysosomal Proteases}

First, APP and APP-CTFs expression was compared between the cell lines used in this study: control naive HEK $\left(\mathrm{HEK}^{\mathrm{ctrl}}\right)$, HEK stably expressing full length wild-type APP (HEK APPWT and HEK cells stably expressing the last 99 carboxy-terminal residues of APP $\left(\mathrm{HEK}^{\mathrm{C} 99}\right)$ fused to the APP signal sequence and two additional residues from APP 695 (Leu, Glu) (Dyrks et al., 1992a, 1993). Overexpression of APP in HEK APPWT and $\mathrm{C} 99$ in $\mathrm{HEK}^{\mathrm{C} 99}$ was confirmed by western-blot analysis (Figure 2A). While in $\mathrm{HEK}^{\mathrm{ctrl}}$ cells, endogenous total APP and APP-CTFs were barely detected in control conditions, they were both increased in HEK APPWT. In $\mathrm{HEK}^{\mathrm{C} 99}$, total APP levels were not affected by C99 overexpression since APP expression is identical to $\mathrm{HEK}^{\mathrm{ctrl}}$ cells. However, $\mathrm{HEK}^{\mathrm{C} 99}$ cells displayed a strong expression of the $\beta$-CTF/C99 fragments. The bands corresponding to $\beta$-CTFs derived from APP processing and overexpressed C99 were identified using the anti-amyloid $\beta$ antibody clone W02 directed againt the A $\beta$ amino acid residues 4-10, which can only recognize $\beta$-CTFs (Figure 2A). The overexpressed C99 was detected at a slightly higher molecular weight than the $\beta$-CTFs derived from endogenous or overexpressed APP due to the presence of the signal sequence and the additional residues (Dyrks et al., 1993; LefrancJullien et al., 2005). To further characterize the cell lines, we evaluated the membrane localisation of APP and APP-CTFs, in particular overexpressed C99, using subcellular fractionation. Results showed that APP and all APP-CTFs, $\alpha$ or $\beta$, endogenous or overexpressed, are membrane-bound, as expected (Figure 2B).

The contribution of pathways responsible for APP-CTFs degradation was then investigated in these models using a pharmacological approach. First, HEK ${ }^{\text {ctrl }}$ and HEK APPWT were treated for $6 \mathrm{~h}$ with the $\gamma$-secretase inhibitor Compound E (CompE) (Yang et al., 2008). APP and APP-CTFs levels were analyzed by Western blotting (Figure 3A). Inhibition

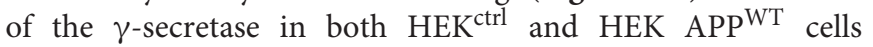
did not modify total APP expression (Figure 3A). In both HEK $^{\text {ctrl }}$ and HEK APPWT cells, APP-CTFs were increased after 

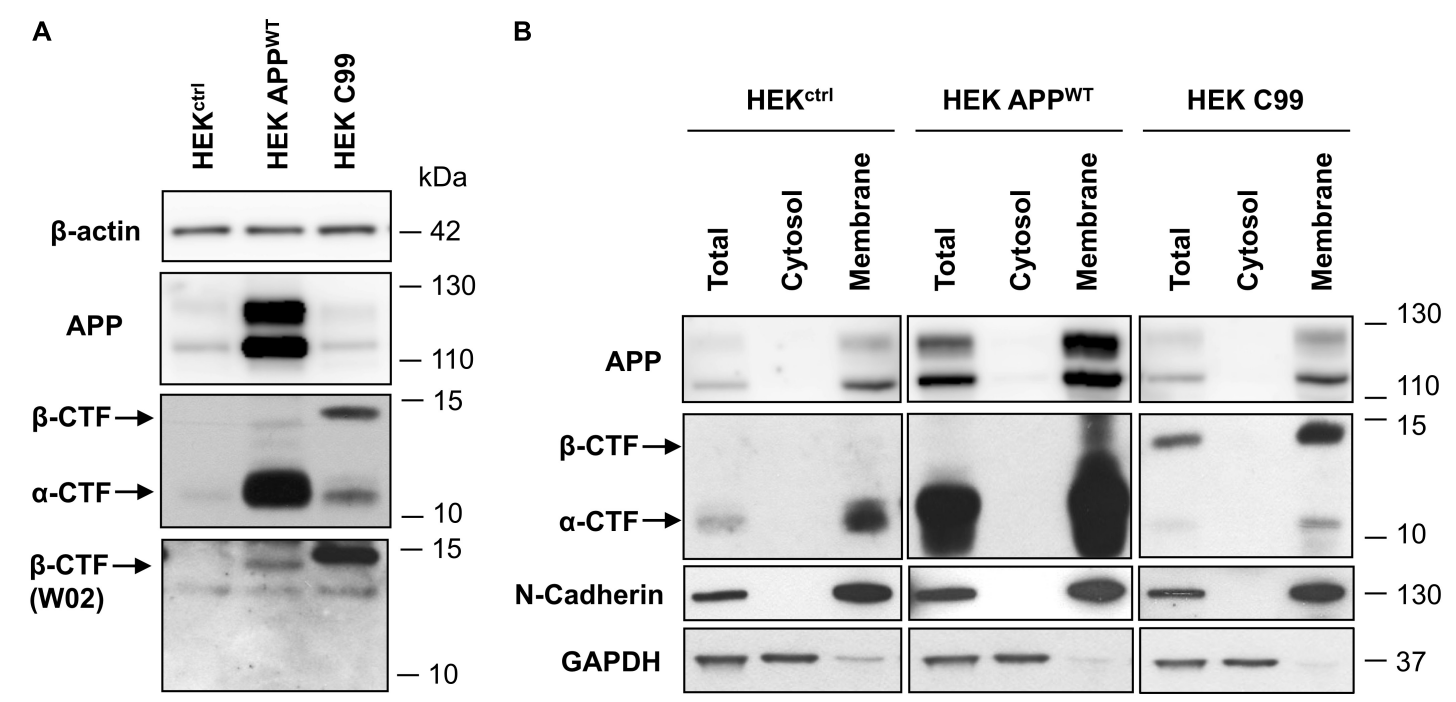

FIGURE 2 | Comparison of APP and C99 expression in the different HEK 293 cell lines used in this study. (A) Western-blot analysis of $\beta$-actin, total APP, APP-CTFs and $\beta$-CTFs (W02) expression in naive HEK 293 cells (HEK ${ }^{\text {ctrl }}$ ) or HEK 293 overexpressing full length APPWT (HEK APPWT) or C99 (HEK ${ }^{\text {C99 }}$ ). $\beta$-actin staining was used as loading control. (B) Western-blot analysis of total APP, APP-CTFs, N-cadherin and GAPDH in total lysates, cytosolic and membrane fractions obtained from $\mathrm{HEK}^{\mathrm{ctrl}}$, HEK APPWT, and HEK ${ }^{\mathrm{C9}}$. GAPDH staining was used as a marker and loading control for total and cytosolic fractions while N-cadherin was used as a marker and loading control for membrane fractions. See Supplementary Figure S3 for corresponding uncropped images of western-blots.

$\gamma$-secretase inhibition with $\alpha$-CTF being the major species observed, indicating that overexpressed APP is processed in a similar manner as its endogenous conterpart. As the major CTFs species observed are $\alpha$-CTFs in these two models, these results demonstrate that there is no bias in the amyloidogenic/non-amyloidogenic balance induced by APP overexpression. $\gamma$-secretase inhibition by CompE increased $\beta$-CTFs expression levels by 6 fold in HEK APPWT (Figure 3B) while the levels of $\mathrm{SAPP} \beta, A \beta_{1-40}$ and $\mathrm{A} \beta_{1-42}$ secretion, measured in the conditioned medium of the cell cultures, were reduced by 55, 85 and 70\%, respectively (Figures 3C,D). These results show that $\gamma$-secretase inhibition reduced $\beta$-CTFs cleavage into $A \beta$ peptides but surprisingly also reduced $\mathrm{sAPP} \beta$ secretion, suggesting that $\gamma$-secretase inhibition led to a reduction of the amyloidogenic processing of APP.

Next, lysosomal proteases were inhibited using the alkalizing agent Chloroquine (CQ), a weak base, or Bafilomycin $\mathrm{A} 1\left(\mathrm{Baf}_{\mathrm{A} 1}\right)$, a vacuolar proton pump inhibitor. Efficiency of CQ and $\mathrm{Baf}_{\mathrm{A} 1}$ treatments were validated using the markers of autophagy: p62 and LC3 lipidation (Supplementary Figures S1A-C). CQ and $\mathrm{Baf}_{\mathrm{A} 1}$ treatments both induced a marked increase in total APP (mainly the mature form, upper band), AICD and APP-CTFs levels, especially $\alpha$-CTFs in both HEK $^{\text {ctrl }}$ and HEK APPWT (Figure 3E). In HEK APPWT treated cells, $\beta$-CTFs expression was increased by $40 \%$ with CQ and by $300 \%$ with Baf $_{\mathrm{A} 1}$ (Figure 3F). Secretion of SAPP $\beta$ was reduced by $40 \%$ with $\mathrm{CQ}$ and by $85 \%$ with $\mathrm{Baf}_{\mathrm{A} 1}$ while $\mathrm{sAPP} \alpha$ was significantly increased by 49 and 230\%, respectively (Figure 3G). CQ and $\mathrm{Baf}_{\mathrm{A} 1}$ treatments also significantly repressed $\mathrm{A} \beta_{1-40}$ and $\mathrm{A} \beta_{1-42}$ secretion (Figure $3 \mathbf{H}$ ). Treatments with $\mathrm{CQ}$ or $\mathrm{Baf}_{A 1}$ inhibited $\beta$-CTFs degradation and reduced $A \beta$ peptides and $\operatorname{APP} \beta$ secretion while they increased $\operatorname{SAPP} \alpha$ secretion, suggesting that the amyloidogenic pathway was reduced in favor of the $\alpha$-secretase cleavage. These results are in agreement with previous reports showing that the endosomal/lysosomal pathway is of particular importance for the whole APP processing, and in particular for efficient amyloidogenic processing (Tam et al., 2016; González et al., 2017; Xu et al., 2017).

Finally, proteasome involvement was assessed using the specific inhibitor lactacystin (Lacta), which potency was validated by detection of polyubiquitinylated proteins in western-blot (Supplementary Figures S1D,E). Total APP and APP-CTFs levels were not significantly modified after $6 \mathrm{~h}$ of lactacystin treatment in $\mathrm{HEK}^{\mathrm{ctrl}}$ or in HEK APPWT treated cells (Figures 3I,J). Moreover, proteasome inhibition did not affect the secretion of $\mathrm{sAPP} \alpha / \mathrm{sAPP} \beta$ or $\mathrm{A} \beta_{1-40}$ and $\mathrm{A} \beta_{1-42}$ peptides in the conditioned medium suggesting that APP processing is not modulated by the proteasome as far as our cell system is concerned (Figures 3K,L).

Together, these results demonstrate that $\gamma$-secretase and lysosomal pathway are directly involved in the processing of sAPP and APP-CTFs that derive from full-length APP, while proteasome is not involved in the degradation of these fragments in these models. Importantly, similar results were obtained both in naive HEK, expressing endogenous levels of APP, and in HEK over-expressing APP ${ }^{\mathrm{WT}}$, thus showing that overexpressed $\mathrm{APP}^{\mathrm{WT}}$ follows the same processing as the endogenous APP, making it a valid model to study APP processing.

\section{Overexpressed C99 Is Processed by $\gamma$-Secretase and the Proteasome}

Given the inconsistency between our results and the literature with regards to the involvement of the proteasome toward 


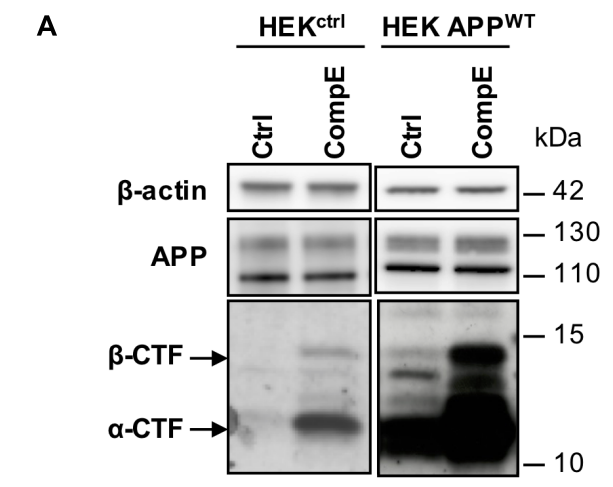

E

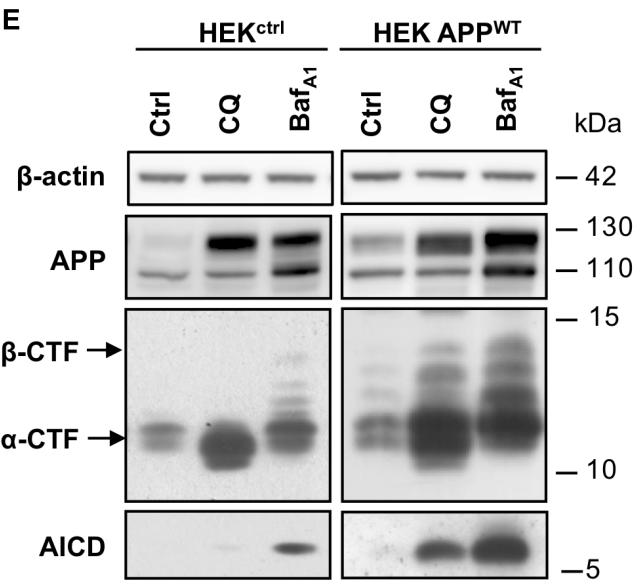

I

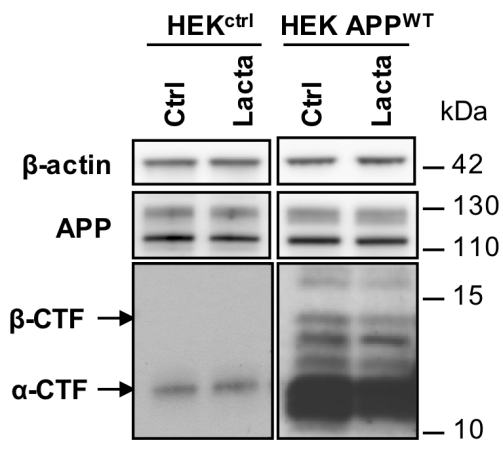

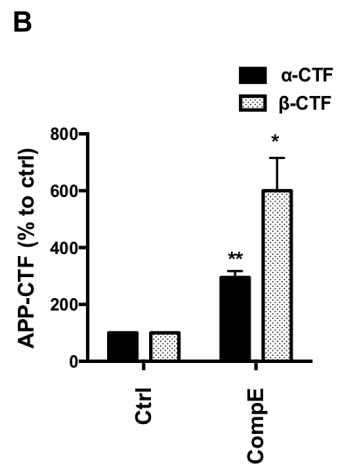

C

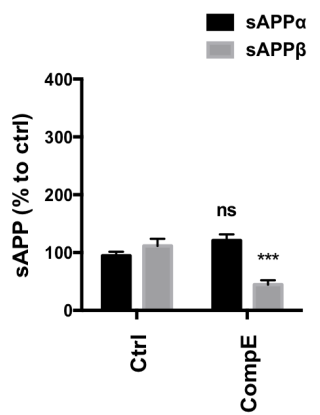

$\mathbf{F}$
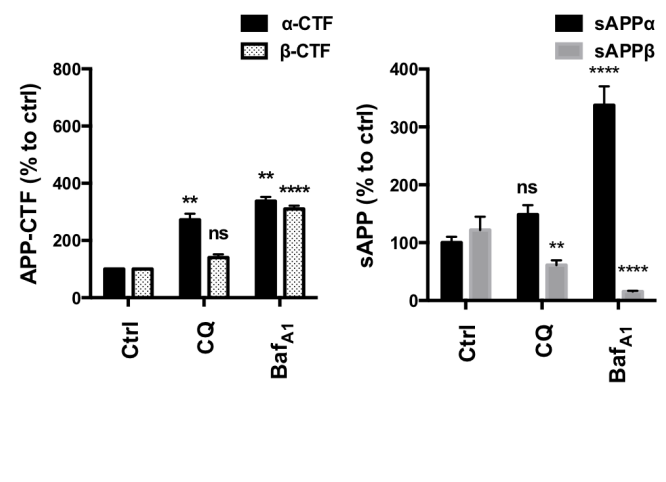

$\mathbf{J}$
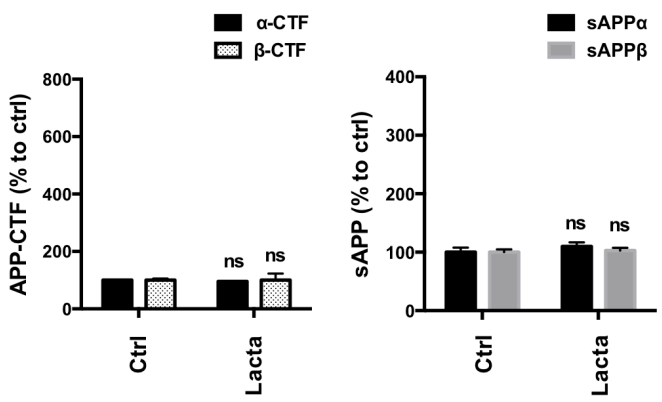

D

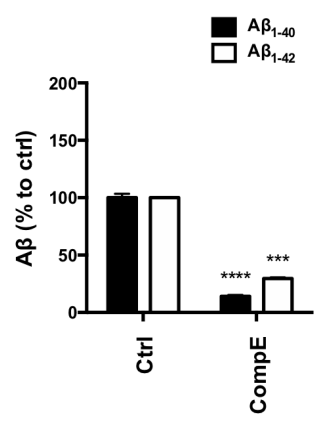

H

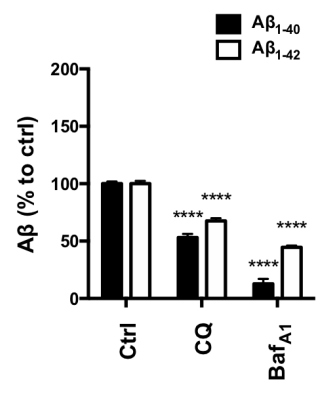

$\mathbf{L}$

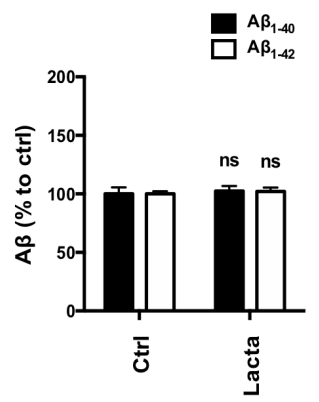

FIGURE 3 | Effect of $\gamma$-secretase, lysosomal proteases or proteasome inhibition on APP processing in HEK ${ }^{\text {crl }}$ and HEK APPWT cells. HEK 293 cells overexpressing or not APPWT were treated with Compound E (CompE, $30 \mathrm{nM}, 6$ h), Chloroquine (CQ, $10 \mu \mathrm{M}, 24$ h), Bafilomycin A1 (Baf $\mathrm{A1}, 100 \mathrm{nM}, 24$ h) or Lactacystin (Lacta, $5 \mu \mathrm{M}, 6 \mathrm{~h}$ ). (A,E,I) Western-blot analysis of $\beta$-actin, total APP and APP-CTFs. $\beta$-actin staining was used as loading control. $\alpha$-CTFs and $\beta$-CTFs are indicated by arrows. (B,F,J) Western-blot quantification of $\alpha$-CTFs (black bars) and $\beta$-CTFs (dotted bars) from HEK APPWT cells, expressed as percentage of the control condition. (C, G,K) Quantification of secreted SAPP $\alpha$ (black bars) and SAPP $\beta$ (gray bars) by electro-chemiluminescence immunoassay from HEK APPWT cells, expressed as percentage of the control condition. ( $\mathbf{D}, \mathbf{H}, \mathbf{L}$ ) Quantification of secreted $A \beta_{1-40}$ (black bars) and $A \beta_{1-42}$ (white bars) measured by ELISA from HEK APPWT cells, expressed as percentage of the control condition. Data are expressed as the mean $\pm \operatorname{SEM}\left(n=3\right.$ independent experiments), ${ }^{*} p<0.05,{ }^{* *} p<0.01$, ${ }^{* * *} p<0.001$, and ${ }^{* * * *} p<0.0001$. See Supplementary Figure $\mathbf{S} 4$ for corresponding uncropped images of western-blots.

APP processing, in particular $\beta$-CTFs, we used $\mathrm{HEK}^{\mathrm{C} 99}$ cells. Indeed, most of the studies, which aim to analyze the role of the proteasome in APP processing, were performed with C99 overexpressing cells. In $\mathrm{HEK}^{\mathrm{C} 99}, \gamma$-secretase inhibition using CompE doubled the amount of C99 levels (Figures 4A,B) and reduced by $30 \%$ the secretion of $A \beta_{1-40}$ peptides in the conditioned medium (Figure $4 \mathrm{C}$ ). $\mathrm{A} \beta_{1-42}$ peptides could not be detected in these conditions, probably due to their low levels of production as described in earlier reports (Lefranc-Jullien et al., 2005). Surprisingly, in sharp contrast with results obtained in HEK APPWT cells, treatments with $\mathrm{CQ}$ or $\mathrm{Baf}_{\mathrm{A} 1}$ did not significantly modify the amount of 
A

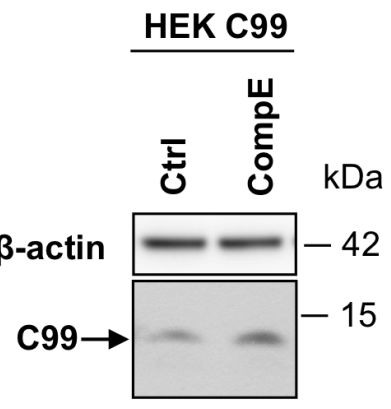

D

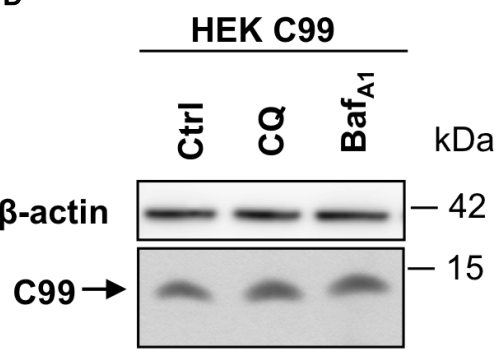

G

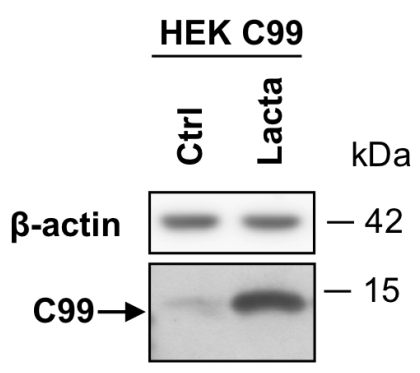

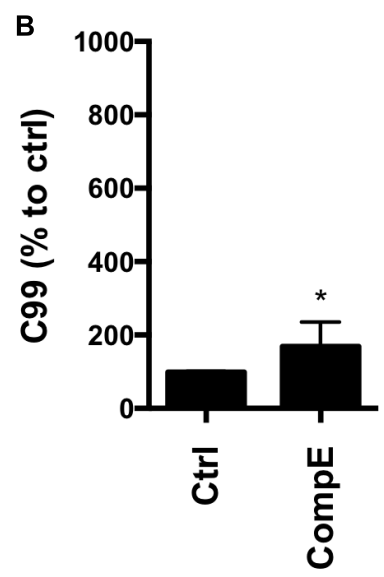

E

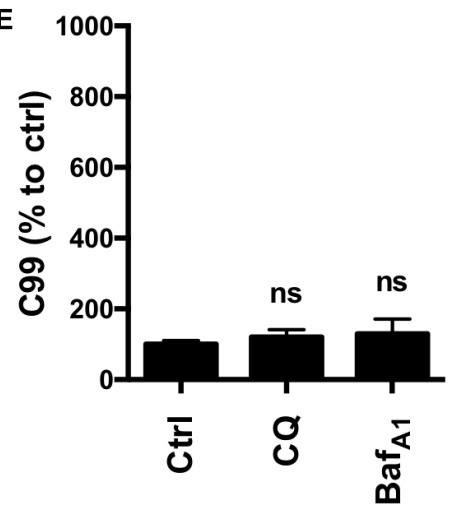

H

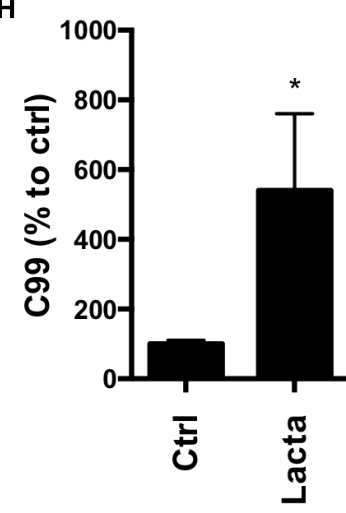

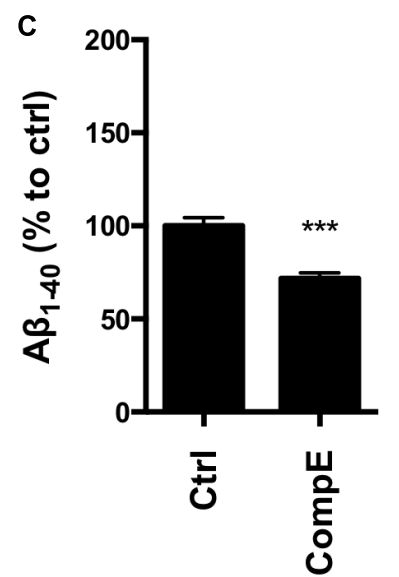
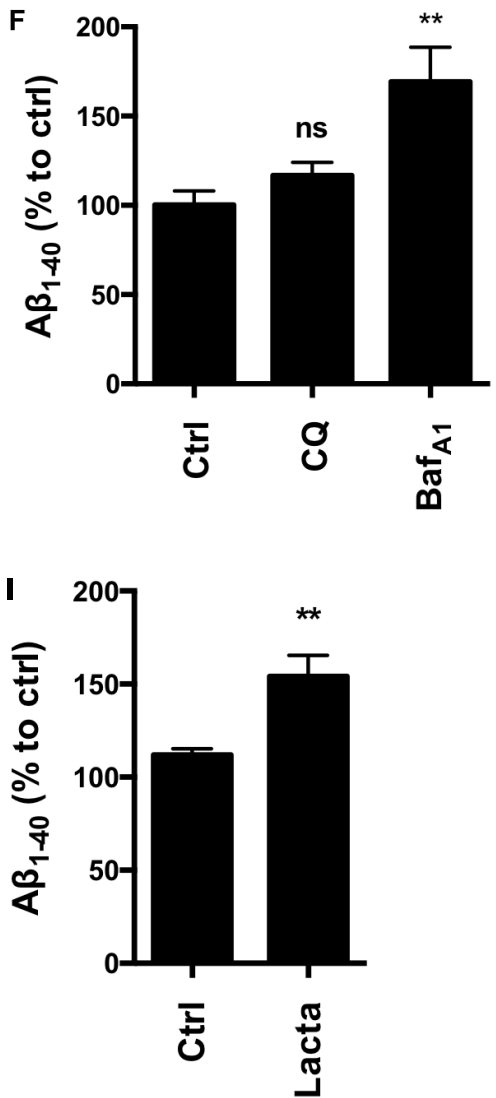

FIGURE 4 | Effect of $\gamma$-secretase, lysosomal proteases or proteasome inhibition on overexpressed C99 processing in HEKC99 cells. HEK 293 cells overexpressing C99 (HEK ${ }^{\mathrm{C} 99}$ ) were treated with Compound E (CompE, $30 \mathrm{nM}, 6$ h), Chloroquine (CQ, $10 \mu \mathrm{M}, 24$ h), Bafilomycin A1 (Baf $\mathrm{A1}, 100$ nM, 24 h) or Lactacystin (Lacta, $5 \mu \mathrm{M}, 6$ h). (A,D,G) Western-blot analysis of $\beta$-actin and C99. (B,E,H) Western-blot quantification of C99 from HEK ${ }^{\text {C99 }}$, expressed as a percentage of the control condition. (C,F,I) ELISA quantification of secreted $A \beta_{1-40}$, expressed as a percentage of the control condition. Data are expressed as the mean \pm SEM, $(n=5$ independent experiments), ${ }^{*} p<0.05,{ }^{* *} p<0.01$, and ${ }^{* * *} p<0.001$. See Supplementary Figure $\mathbf{S} 5$ for corresponding uncropped images of western-blots.

C99 (Figures 4D,E), suggesting that the lysosomal pathway is not the main degradation route for overexpressed C99. However, while CQ had no effect on $\mathrm{A} \beta_{1-40}$ peptides secretion, Baf $_{\mathrm{A} 1}$ induced a $50 \%$ increase of $\mathrm{A} \beta_{1-40}$ peptides secretion (Figure 4F). Finally, proteasome inhibition with lactacystin induced a significant increase of C99 compared to the control condition (Figures 4G,H). Moreover, lactacystin also induced a $50 \%$ increase in $A \beta_{1-40}$ peptides secretion (Figure $4 \mathrm{I}$ ). To ascertain that this effect was not related to off-target effects of lactacystin, we used two other proteasomal inhibitors to validate these data. Similar results were obtained using Epoxomicin and MG132, further supporting the observation that C99 is processed by the proteasome in this model (Supplementary Figure S2A). Finally, APP overexpression was also reported to disturb 
proteasome activity (Matsumoto et al., 2006). To ascertain that the inhibitory effect of lactacystin on proteasome activity was conserved in HEK APP ${ }^{\mathrm{WT}}$ cells, we compared the accumulation of polyubiquitinylated proteins following lactacystin treatment in the cell lines. Our data established that lactacystin treatment led to a similar increase of polyubiquitinylated proteins in all the cell lines (Supplementary Figures S2B,C), demonstrating that the differential effect of proteasome on the degradation of C99 and $\beta$-CTF cannot be attributed to an impairement of the proteasome activity in HEK APPWT cells.

Taken together and in comparison to control HEK cells expressing endogenous $\beta$-CTFs (Figure 2), these results show that overexpressed C99 is mainly processed by the proteasome and to a lesser extent by $\gamma$-secretase. However, in contrast with APP-derived $\beta$-CTFs, the lysosomal pathway does not seem to be involved in the degradation of overexpressed C99. Overall, these data strongly suggest that overexpressed C99 does not follow the same degradation route as the endogenously produced APP-CTF fragments.

\section{Proteasomal Involvement Toward APP Processing in Primary Neuronal Cells Infected With APPWT or C99}

Finally, to exclude any cell line dependent effect, we used primary rat neuronal cells that were infected or not with $\mathrm{APP}{ }^{\mathrm{WT}}$ or $\mathrm{C} 99$ to validate the results regarding the proteasome involvement in $\beta$-CTFs processing in a more physiological model. Lactacystin treatment did not significantly modify APP-CTFs expression in control or APPWT infected neurons (Figures $5 \mathbf{A}, \mathbf{B}$ ), as it was observed in HEK cells. However, overexpressed C99 was significantly accumulated in C99 infected neurons under

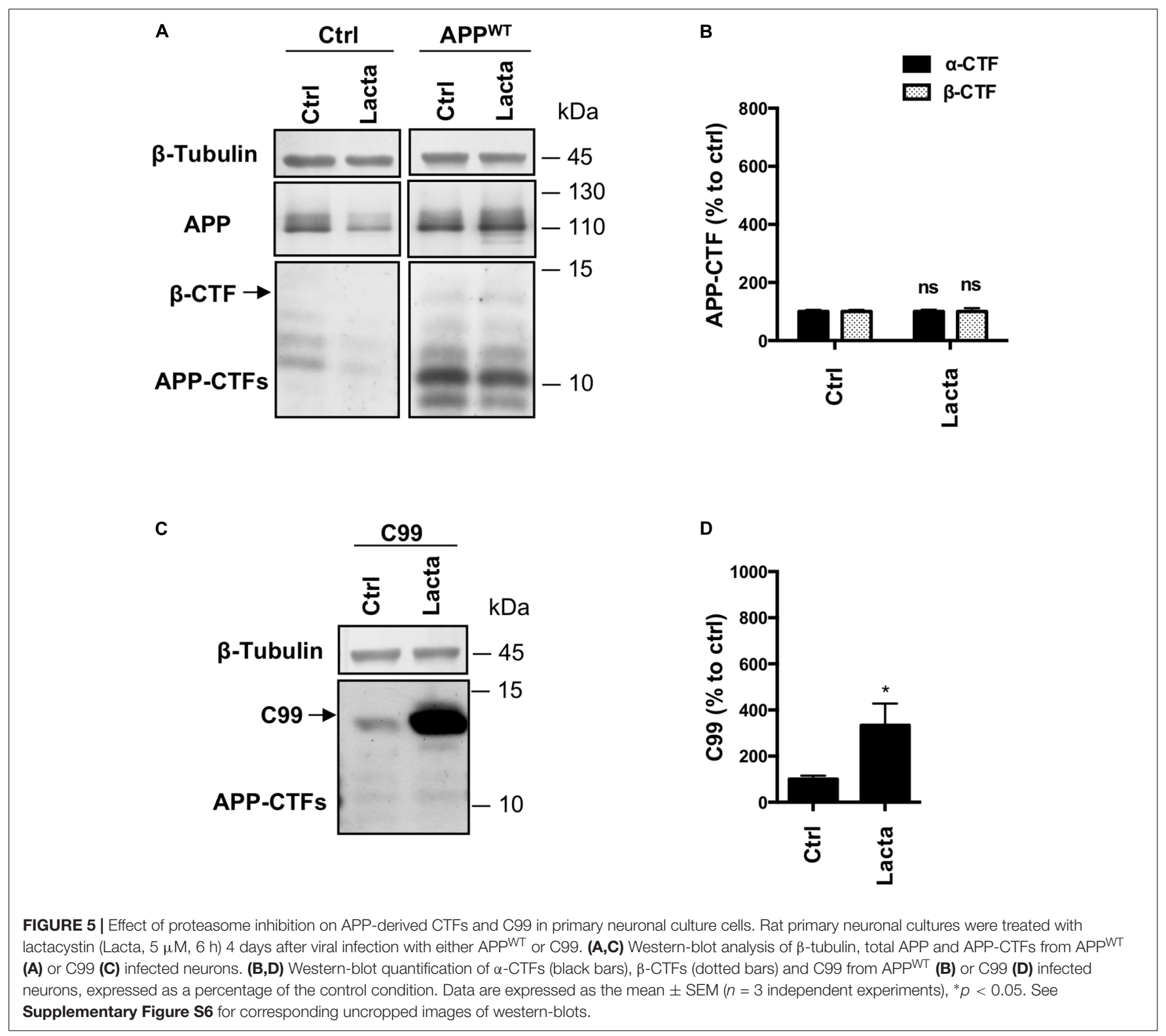


lactacystin treatment (Figures 5C,D). Altogether, these results showed that the proteasome is not involved in the degradation of APP-derived CTFs in cultured rat neurons, whereas proteasomal inhibition strongly repressed overexpressed C99 degradation. These data are in agreement with results obtained in HEK APPWT and $\mathrm{HEK}^{\mathrm{C} 99}$ cells, respectively.

\section{DISCUSSION}

APP metabolism is a key feature in the onset and progression of $\mathrm{AD}$ as it is at the origin of $\beta$-CTFs accumulation and $\mathrm{A} \beta$ peptides production. Drugs that improve the clearance of APP metabolites would possibly protect from the detrimental effects of APP-CTFs and A $\beta$ peptides accumulation. Therefore, a better understanding of alternative degradation pathways and molecular factors modulating $\beta$-CTFs accumulation is of interest and could uncover potential interesting pharmacological targets.

Herein, we showed that APP-CTFs produced from endogenous or overexpressed full-length APP are mainly processed by $\gamma$-secretase and the endosomal/lysosomal pathway (observations are summarized in Figure 6A). Interestingly, $\gamma$-secretase inhibition did not only led to a reduction of $A \beta$ peptides secretion but also to a decreased secretion of sAPP $\beta$. This is, to the best of our knowledge, the first report suggesting that $\gamma$-secretase inhibition also repress to some extend $\beta$-secretase cleavage of APP. The mechanism by which this cross-inhibition occur will require further investigations. It could be speculated that $\gamma$-secretase substrates may include proteins that could be important for the targeting of BACE or the acidification of intracellular compartments; or that inhibiting $\gamma$-secretase activity could reroute APP toward an alternative $\beta$-secretase activity, i.e., meprin $\beta$, thus producing $\operatorname{sAP} \beta$ that would not be recognized by the electro-chemiluminescence immunoassay kit used in this study.

Our results also confirmed that besides being cleaved by $\gamma$-secretase, APP-CTFs are efficiently degraded by the endosomal/lysosomal pathway, as it was widely reported (Tam et al., 2016; González et al., 2017; Xu et al., 2017). Along with reducing APP-CTFs degradation, drugs that were used to inhibit the endosomal/lysosomal pathway significantly reduced the secretion of $A \beta$ peptides and sAPP $\beta$ species. As we previously

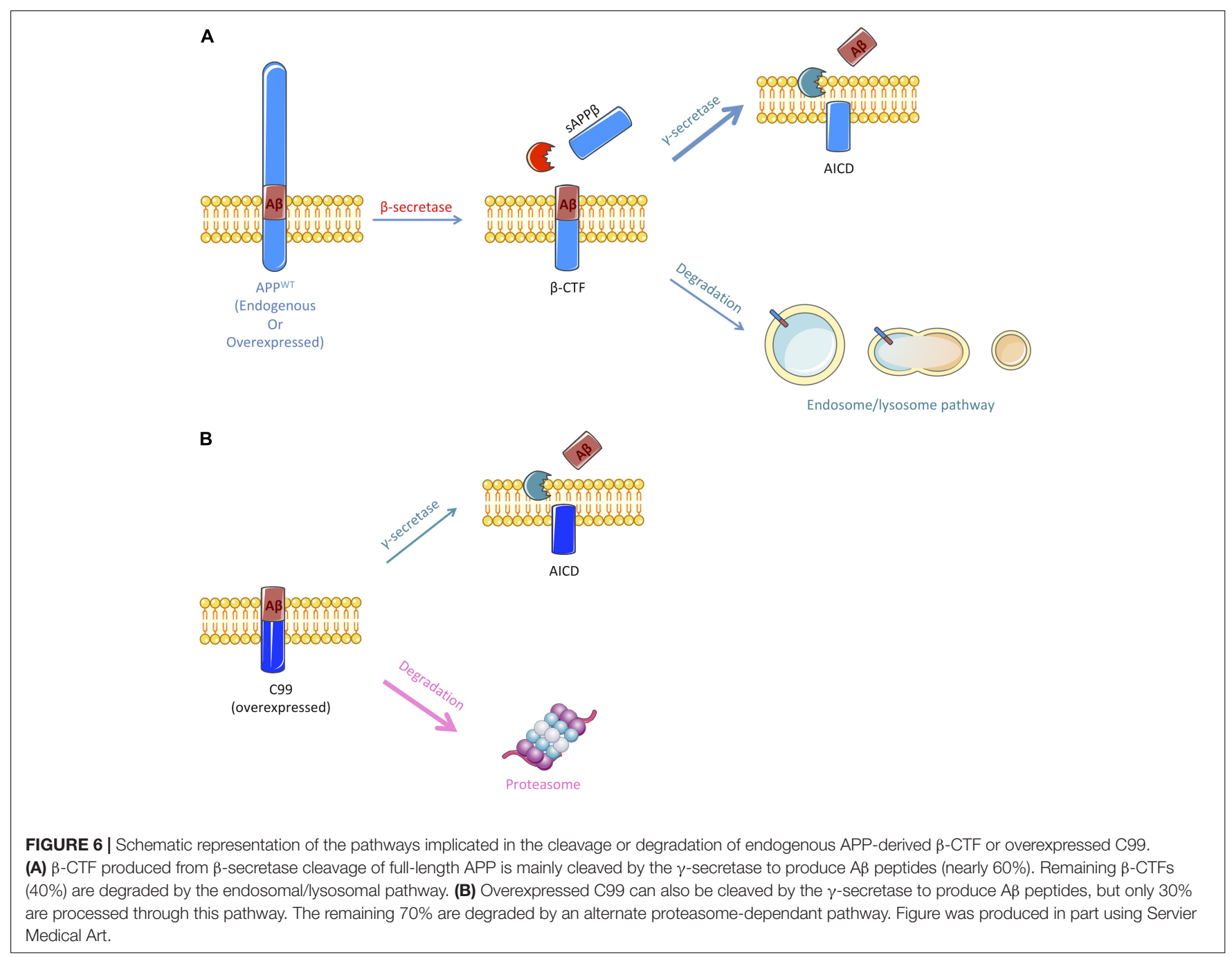


showed that the inhibition of the endosomal/lysosomal pathway does not alter $\gamma$-secretase activity (Vingtdeux et al., 2007a), these results suggest that there could be an impairment of the extracellular release of $\mathrm{A} \beta$ and sAPP $\beta$ from recycling compartments or that the $\beta$-secretase cleavage of APP is inhibited by these lysomotropic agents. The cleavage of APP by BACE1 occurs in acidic endosomal compartments, with an optimal activity at pH 4.5 (Vassar et al., 1999; Sun and Roy, 2017). Thus, it is not surprising that these drugs, which act by reducing the acidification of the endosomal and lysosomal compartments, would lead to an inhibition of BACE1-mediated APP processing and a parallel increase of sAPP $\alpha$ secretion, which could result from a redirection of APP to the non-amyloidogenic pathway. The development of drugs/molecules that derive from the CQ structure and share its effects on APP processing is an interesting strategy that is currently developed to tackle $\mathrm{AD}$ (Melnyk et al., 2015). Interestingly, we recently described the identification of $\mathrm{CQ}$ derivatives that retained their effects toward $\mathrm{A} \beta$ secretion without impacting APP-CTFs accumulation through lysomotropic activity (Gay et al., 2018).

In sharp contrast to APP derived $\beta$-CTFs degradation, we found that overexpressed C99 was mainly degraded by the proteasome and to a lower extent by $\gamma$-secretase (Figure 6B). Indeed, lactacystin led to a strong accumulation of overexpressed C99 that was accompanied by an increase in $\mathrm{A} \beta_{1-40}$ peptides secretion. The strong accumulation of C99 following proteasome inhibition could lead to an upsurge in $\gamma$-secretase substrate availability and therefore to an increase in $\mathrm{A} \beta$ peptides production, without affecting $\gamma$-secretase activity. However, we cannot exclude the possibility that $\gamma$-secretase activity could be altered following proteasome inhibition. Indeed, components of the $\gamma$-secretase complex have been shown to be ubiquitinylated and thus suggested to be handled by the proteasome (Kim et al., 1997; Marambaud et al., 1998; He et al., 2006, 2007).

The different processing of overexpressed C99 as compared to APP-derived $\beta$-CTFs by the proteasome could be an artefactual consequence of the overexpression. Indeed, several reports have shown that overexpressed proteins can be processed in an artefactual way by the proteasome (Dunys et al., 2006). Dunys et al. also proposed that lactacystin could activate CMV promoters thus, leading to an artefactual increase in expression levels. However, expression of full-length APP, which was also overexpressed in our HEK APPWT model, was not affected by lactacystin treatment. In addition, two other proteasome inhibitors also led to C99 increase. The most straightforward conclusion here is that, when ectopically over-expressed, C99 is recognized as a truncated membrane protein that will undergo ER-associated degradation (ERAD) mediated by the proteasome (Avci and Lemberg, 2015; Jang et al., 2017). This is not the case for APP-CTFs that are endogenously produced along the endosome/lysosome pathway. However, it will be interesting to determine whether mutations in APP that are associated with familial forms of AD could affect APP processing by the endosomal/lysosomal or proteasomal pathway.

In conclusion, our data show that APP-derived CTFs are processed principally by the $\gamma$-secretase and alternatively degraded by lysosomes. Indeed, the physiological processing of
APP by $\alpha$ - or $\beta$-secretase relies on the endosomal/lysosomal pathway, which dysfunction leads to a complete disturbance of APP metabolites. However, a direct degradation of APP-derived CTFs by a proteasome-dependent pathway is not supported experimentally in this study. In sharp contrast, C99 chimeric construct is mainly processed by a proteasome-dependent mechanism and to a lesser extent by $\gamma$-secretase. Hence, homologies between APP-derived $\beta$-CTFs and overexpressed C99 processing are likely restricted to their processing by $\gamma$-secretase, therefore caution should be taken when using this model to study $\beta$-CTFs biology.

\section{AUTHOR CONTRIBUTIONS}

PK-C, J-NO, LB, NS, and VV contributed conception and design of the study. CE, PK-C, MC, RO, BT, and VV carried out the experiments. CE performed the statistical analysis. PM provided study materials. CE, NS, and VV wrote the manuscript. All authors contributed to manuscript revision, read and approved the submitted version.

\section{FUNDING}

This work was supported by the ANR VIDALZ (ANR-15-CE180002) and the Labex DISTALZ (Development of Innovative Strategies for a Transdisciplinary Approach to Alzheimer's Disease). CE holds a doctoral scholarship from Lille 2 University.

\section{ACKNOWLEDGMENTS}

We thank Prof. F. Checler for kindly providing us with cell lines. We would also like to thank Manon Domise, Florent Sauve, and Chloe Lamarre for their technical assistance. This article was posted as a pre-print at BioRxiv (Evrard et al., 2018).

\section{SUPPLEMENTARY MATERIAL}

The Supplementary Material for this article can be found online at: $\quad$ https://www.frontiersin.org/articles/10.3389/fncel.2018. 00435/full\#supplementary-material

FIGURE S1 | Validation of inhibitors efficacy. HEK 293 cells were treated with Chloroquine (CQ, $10 \mu \mathrm{M}, 24$ h), Bafilomycin A1 (Baf $\mathrm{A1}, 100 \mathrm{nM}, 24 \mathrm{~h})$ or Lactacystin (Lacta, $5 \mu \mathrm{M}, 6$ h). (A,D) Western-blot analysis of $\beta$-actin, p62, LC3-B and polyubiquitinylated proteins. $\beta$-actin staining was used as loading control. (B,C,E) Western-blot quantification of p62, LC3-II/LC3-I ratio and poly ubiquitin from HEK APPWT cells, expressed as a percentage of the control condition. Inhibition of lysosomal flux was validated by the increase of two markers associated with autophagy: p62 and LC3-I lipidation into LC3-II and inhibition of proteasomal degradation was validated by the accumulation of polyubiquitinylated proteins in cells. Data are expressed as the mean \pm SEM $(n=3$ independent experiments), $* * p<0.01,{ }^{* * *} p<0.001$, and $* * * * p<0.0001$.

FIGURE S2 | Representative effects of other proteasome inhibitors on overexpressed C99 processing in HEK ${ }^{\mathrm{C} 99}$ cells and proteasome activity in the different HEK 293 cell lines used in this study. (A) Western-blot analysis of $\beta$ actin and C99 in HEK ${ }^{\mathrm{C} 99}$ treated with Expoxomicin (Epoxo, $1 \mu \mathrm{M}, 6 \mathrm{~h}$ ) or MG132 (10 $\mu \mathrm{M}, 6$ h). $\beta$-actin staining was used as loading control $(n=3$ independent 
experiments). (B) Western-blot analysis of $\beta$-actin and polyubiquitinylated proteins expression in naive HEK 293 cells (HEK ${ }^{\text {ctrl }}$ ), and HEK 293 overexpressing full length APPWT (HEK APPWT) or C99 (HEKC99) cells treated with Lactacystin (Lacta, $5 \mu \mathrm{M}, 6 \mathrm{~h}$ ) or not (Ctrl). $\beta$-actin staining was used as loading control. (C) Western-blot quantification of polyubiquitinylated proteins, expressed as percentage of the control condition. Data are expressed as mean \pm SEM $(n=3$ independent experiments), ${ }^{* *} p<0.01$ using the unpaired Student's test for pairwise comparisons between control and lactacystin conditions. Using the one way ANOVA with Bonferroni's multiple

\section{REFERENCES}

Andrew, R. J., Kellett, K. A. B., Thinakaran, G., and Hooper, N. M. (2016). A greek tragedy: the growing complexity of alzheimer amyloid precursor protein proteolysis. J. Biol. Chem. 291, 19235-19244. doi: 10.1074/jbc.R116. 746032

Avci, D., and Lemberg, M. K. (2015). Clipping or extracting: two ways to membrane protein degradation. Trends Cell Biol. 25, 611-622. doi: 10.1016/j.tcb.2015.07. 003

Baranger, K., Bonnet, A. E., Girard, S. D., Paumier, J., García-González, L., Elmanaa, W., et al. (2017). MT5-MMP promotes Alzheimer's pathogenesis in the frontal cortex of 5xFAD mice and APP trafficking in vitro. Front. Mol. Neurosci. 9:163. doi: 10.3389/fnmol.2016.00163

Baranger, K., Khrestchatisky, M., and Rivera, S. (2016a). MT5-MMP, just a new APP processing proteinase in Alzheimer's disease? J. Neuroinflammation 13:167. doi: 10.1186/s12974-016-0633-4

Baranger, K., Marchalant, Y., Bonnet, A. E., Crouzin, N., Carrete, A., Paumier, J. M., et al. (2016b). MT5-MMP is a new pro-amyloidogenic proteinase that promotes amyloid pathology and cognitive decline in a transgenic mouse model of Alzheimer's disease. Cell. Mol. Life Sci. 73, 217-236. doi: 10.1007/s00018-0151992-1

Becker-Pauly, C., and Pietrzik, C. U. (2017). The metalloprotease meprin $\beta$ is an alternative $\beta$-secretase of APP. Front. Mol. Neurosci. 9:159. doi: 10.3389/fnmol. 2016.00159

Bien, J., Jefferson, T., Čauševič, M., Jumpertz, T., Munter, L., Multhaup, G., et al. (2012). The metalloprotease meprin $\beta$ generates amino terminal-truncated amyloid $\beta$ peptide species. J. Biol. Chem. 287, 33304-33313. doi: 10.1074/jbc. M112.395608

Dunys, J., Kawarai, T., Wilk, S., St George-Hyslop, P., Alves da Costa, C., and Checler, F. (2006). Catabolism of endogenous and overexpressed APH1a and PEN2: evidence for artifactual involvement of the proteasome in the degradation of overexpressed proteins. Biochem. J. 394, 501-509. doi: 10.1042/ BJ20051197

Dyrks, T., Dyrks, E., Hartmann, T., Masters, C., and Beyreuther, K. (1992a). Amyloidogenicity of beta A4 and beta A4-bearing amyloid protein precursor fragments by metal-catalyzed oxidation. J. Biol. Chem. 267, 18210-18217.

Dyrks, T., Dyrks, E., Masters, C., and Beyreuther, K. (1992b). Membrane inserted APP fragments containing the $\beta A 4$ sequence of Alzheimer's disease do not aggregate. FEBS Lett. 309, 20-24. doi: 10.1016/0014-5793(92)80730-5

Dyrks, T., Dyrks, E., Mönning, U., Urmoneit, B., Turner, J., and Beyreuther, K. (1993). Generation of $\beta A 4$ from the amyloid protein precursor and fragments thereof. FEBS Lett. 335, 89-93. doi: 10.1016/0014-5793(93)80446-2

Evrard, C., Kienlen-Campard, P., Opsomer, R., Tasiaux, B., Octave, J.-N., Buée, L., et al. (2018). Contribution of the endosomal-lysosomal and proteasomal systems in Amyloid- $\beta$ precursor protein derived fragments processing. bioRxiv [Preprint]. doi: 10.1101/300921

Flood, F., Murphy, S., Cowburn, R. F., Lannfelt, L., Walker, B., and Johnston, J. A. (2005). Proteasome-mediated effects on amyloid precursor protein processing at the gamma-secretase site. Biochem. J. 385, 545-550. doi: 10.1042/BJ20041145

Gay, M., Evrard, C., Descamps, F., Carato, P., Renault, N., Coevoet, M., et al. (2018). A phenotypic approach to the discovery of compounds that promote non-amyloidogenic processing of the amyloid precursor protein: toward a new profile of indirect $\beta$-secretase inhibitors. Eur. J. Med. Chem. 159, 104-125. doi: 10.1016/j.ejmech.2018.08.092

González, A. E., Muñoz, V. C., Cavieres, V. A., Bustamante, H. A., Cornejo, V. H., Januário, Y. C., et al. (2017). Autophagosomes cooperate in the degradation comparisons test for comparisons between cell lines, no significant diffence was observed.

FIGURE S3 | Uncropped images of western-blot presented in Figure 2.

FIGURE S4 | Uncropped images of western-blot presented in Figure 3.

FIGURE S5 | Uncropped images of western-blot presented in Figure 4.

FIGURE S6 | Uncropped images of western-blot presented in Figure 5

of intracellular C-terminal fragments of the amyloid precursor protein via the MVB/lysosomal pathway. FASEB J. 31, 2446-2459. doi: 10.1096/fj.201600713R

He, G., Qing, H., Cai, F., Kwok, C., Xu, H., Yu, G., et al. (2006). Ubiquitinproteasome pathway mediates degradation of APH-1. J. Neurochem. 99, 14031412. doi: 10.1111/j.1471-4159.2006.04184.x

He, G., Qing, H., Tong, Y., Cai, F., Ishiura, S., and Song, W. (2007). Degradation of nicastrin involves both proteasome and lysosome. J. Neurochem. 101, 982-992. doi: 10.1111/j.1471-4159.2007.04449.x

Hung, S.-Y., and Fu, W.-M. (2017). Drug candidates in clinical trials for Alzheimer's disease. J. Biomed. Sci. 24:47. doi: 10.1186/s12929-017-0355-7

Jäckle, F., Schmidt, F., Wichert, R., Arnold, P., Prox, J., Mangold, M., et al. (2015). Metalloprotease meprin $\beta$ is activated by transmembrane serine protease matriptase-2 at the cell surface thereby enhancing APP shedding. Biochem. J. 470, 91-103. doi: 10.1042/BJ20141417

Jang, J. K., Park, K. J., Lee, J. H., Ko, K. Y., Kang, S., and Kim, I. Y. (2017). Selenoprotein S is required for clearance of C99 through endoplasmic reticulum-associated degradation. Biochem. Biophys. Res. Commun. 486, 444 450. doi: 10.1016/j.bbrc.2017.03.060

Kaether, C., Schmitt, S., Willem, M., and Haass, C. (2006). Amyloid precursor protein and Notch intracellular domains are generated after transport of their precursors to the cell surface. Traffic 7, 408-415. doi: 10.1111/j.1600-0854.2006. 00396.x

Kienlen-Campard, P., Miolet, S., Tasiaux, B., and Octave, J. N. (2002). Intracellular amyloid- $\beta 1-42$, but not extracellular soluble amyloid- $\beta$ peptides, induces neuronal apoptosis. J. Biol. Chem. 277, 15666-15670. doi: 10.1074/jbc. M200887200

Kim, T.-W., Pettingell, W. H., Hallmark, O. G., Moir, R. D., Wasco, W., and Tanzi, R. E. (1997). Endoproteolytic cleavage and proteasomal degradation of presenilin 2 in transfected cells. J. Biol. Chem. 272, 11006-11010. doi: 10.1074/ jbc.272.17.11006

Lauritzen, I., Pardossi-Piquard, R., Bauer, C., Brigham, E., Abraham, J.-D., Ranaldi, S., et al. (2012). The -secretase-derived C-terminal fragment of APP, C99, but not A, is a key contributor to early intraneuronal lesions in tripletransgenic mouse hippocampus. J. Neurosci. 32, 16243-16255. doi: 10.1523/ JNEUROSCI.2775-12.2012

Lefranc-Jullien, S., Lisowski, V., Hernandez, J.-F., Martinez, J., and Checler, F. (2005). Design and characterization of a new cell-permeant inhibitor of the beta-secretase BACE1. Br. J. Pharmacol. 145, 228-235. doi: 10.1038/sj.bjp. 0706183

Lichtenthaler, S. F. (2011). Alpha-secretase in Alzheimer's disease: molecular identity, regulation and therapeutic potential. J. Neurochem. 116, 10-21. doi: $10.1111 / \mathrm{j} .1471-4159.2010 .07081 . x$

Marambaud, P., Ancolio, K., Lopez-Perez, E., and Checler, F. (1998). Proteasome inhibitors prevent the degradation of familial Alzheimer's disease-linked presenilin 1 and potentiate A beta 42 recovery from human cells. Mol. Med. 4, 147-157. doi: 10.1007/BF03401912

Marambaud, P., Chevallier, N., Barelli, H., Wilk, S., and Checler, F. (1997). Proteasome contributes to the a-secretase pathway of amyloid precursor protein in human cells. J. Neurochem. 68, 698-703. doi: 10.1046/j.1471-4159.1997. 68020698.x

Matsumoto, K., Akao, Y., Yi, H., Shamoto-Nagai, M., Maruyama, W., and Naoi, M. (2006). Overexpression of amyloid precursor protein induces susceptibility to oxidative stress in human neuroblastoma SH-SY5Y cells. J. Neural Transm. 113, 125-135. doi: 10.1007/s00702-005-0318-0

Melnyk, P., Vingtdeux, V., Burlet, S., Eddarkaoui, S., Grosjean, M.-E., Larchanche, P.-E., et al. (2015). Chloroquine and chloroquinoline derivatives as models for 
the design of modulators of amyloid peptide precursor metabolism. ACS Chem. Neurosci. 6, 559-569. doi: 10.1021/cn5003013

Morel, E., Chamoun, Z., Lasiecka, Z. M., Chan, R. B., Williamson, R. L., Vetanovetz, C., et al. (2013). Phosphatidylinositol-3-phosphate regulates sorting and processing of amyloid precursor protein through the endosomal system. Nat. Commun. 4:2250. doi: 10.1038/ncomms3250

Nunan, J., Shearman, M. S., Checler, F., Cappai, R., Evin, G., Beyreuther, K., et al. (2001). The C-terminal fragment of the Alzheimer's disease amyloid protein precursor is degraded by a proteasome-dependent mechanism distinct from gamma-secretase. Eur. J. Biochem. 268, 5329-5336. doi: 10.1046/j.0014-2956. 2001.02465.x

Nunan, J., Williamson, N. A., Hill, A. F., Sernee, M. F., Masters, C. L., and Small, D. H. (2003). Proteasome-mediated degradation of the C-terminus of the Alzheimer's disease beta-amyloid protein precursor: effect of C-terminal truncation on production of beta-amyloid protein. J. Neurosci. Res. 74, 378-385. doi: $10.1002 /$ jnr.10646

Pera, M., Alcolea, D., Sánchez-Valle, R., Guardia-Laguarta, C., Colom-Cadena, M., Badiola, N., et al. (2013). Distinct patterns of APP processing in the CNS in autosomal-dominant and sporadic Alzheimer disease. Acta Neuropathol. 125, 201-213. doi: 10.1007/s00401-012-1062-9

Pitsi, D., Kienlen-Campard, P., and Octave, J. N. (2002). Failure of the interaction between presenilin 1 and the substrate of gamma-secretase to produce Abeta in insect cells. J. Neurochem. 83, 390-399. doi: 10.1046/j.1471-4159.2002. 01138.x

Sergeant, N., David, J. P., Champain, D., Ghestem, A., Wattez, A., and Delacourte, A. (2002). Progressive decrease of amyloid precursor protein carboxy terminal fragments (APP-CTFs), associated with tau pathology stages, in Alzheimer's disease. J. Neurochem. 81, 663-672. doi: 10.1046/j.1471-4159. 2002.00901.x

Skovronsky, D. M., Pijak, D. S., Doms, R. W., and Lee, V. M.-Y. (2000). A distinct ER/IC $\gamma$-secretase competes with the proteasome for cleavage of APP $\dagger$. Biochemistry 39, 810-817. doi: 10.1021/bi991728z

Sun, J., and Roy, S. (2017). The physical approximation of APP and BACE-1: a key event in Alzheimer's disease pathogenesis. Dev. Neurobiol. 78, 340-347. doi: 10.1002/dneu.22556

Tam, J. H. K., Rebecca Cobb, M., Seah, C., and Pasternak, S. H. (2016). Tyrosine binding protein sites regulate the intracellular trafficking and processing of amyloid precursor protein through a novel lysosome-directed pathway. PLoS One 11:e0161445. doi: 10.1371/journal.pone.0161445

Tamayev, R., Matsuda, S., Arancio, O., and D'Adamio, L. (2012). $\beta$ - but not $\gamma$-secretase proteolysis of APP causes synaptic and memory deficits in a mouse model of dementia. EMBO Mol. Med. 4, 171-179. doi: 10.1002/emmm. 201100195

Vassar, R., Bennett, B. D., Babu-Khan, S., Kahn, S., Mendiaz, E. A., Rogers, G., et al. (1999). B-secretase cleavage of Alzheimer's amyloid precursor protein by the transmembrane aspartic protease BACE. Science 286, 735-741. doi: 10.1126/ science.286.5440.735

Vingtdeux, V., Hamdane, M., Bégard, S., Loyens, A., Delacourte, A., Beauvillain, J. C., et al. (2007a). Intracellular $\mathrm{pH}$ regulates amyloid precursor protein intracellular domain accumulation. Neurobiol. Dis. 25, 686-696. doi: 10.1016/ j.nbd.2006.09.019

Vingtdeux, V., Hamdane, M., Loyens, A., Gelé, P., Drobeck, H., Bégard, S., et al. (2007b). Alkalizing drugs induce accumulation of amyloid precursor protein by-products in luminal vesicles of multivesicular bodies. J. Biol. Chem. 282, 18197-18205. doi: 10.1074/jbc.M609475200

Vingtdeux, V., Hamdane, M., Gompel, M., Bégard, S., Drobecq, H., Ghestem, A., et al. (2005). Phosphorylation of amyloid precursor carboxy-terminal fragments enhances their processing by a gamma-secretase-dependent mechanism. Neurobiol. Dis. 20, 625-637. doi: 10.1016/j.nbd.2005.05.004

Vingtdeux, V., and Marambaud, P. (2012). Identification and biology of $\alpha$-secretase. J. Neurochem. 120, 34-45. doi: 10.1111/j.1471-4159.2011.07477.x

Wang, X., Zhou, X., Li, G., Zhang, Y., Wu, Y., and Song, W. (2017). Modifications and trafficking of APP in the pathogenesis of Alzheimer's disease. Front. Mol. Neurosci. 10:294. doi: 10.3389/fnmol.2017.00294

Willem, M., Tahirovic, S., Busche, M. A., Ovsepian, S. V., Chafai, M., Kootar, S., et al. (2015). $\eta$-Secretase processing of APP inhibits neuronal activity in the hippocampus. Nature 526, 443-447. doi: 10.1038/nature14864

$\mathrm{Xu}$, S., Zhang, L., and Brodin, L. (2017). Overexpression of SNX7 reduces A $\beta$ production by enhancing lysosomal degradation of APP. Biochem. Biophys. Res. Commun. 495, 12-19. doi: 10.1016/j.bbrc.2017.10.127

Yang, T., Arslanova, D., Gu, Y., Augelli-Szafran, C., and Xia, W. (2008). Quantification of gamma-secretase modulation differentiates inhibitor compound selectivity between two substrates Notch and amyloid precursor protein. Mol. Brain 1:15. doi: 10.1186/1756-6606-1-15

Zhang, Z., Song, M., Liu, X., Su Kang, S., Duong, D. M., Seyfried, N. T., et al. (2015). Delta-secretase cleaves amyloid precursor protein and regulates the pathogenesis in Alzheimer's disease. Nat. Commun. 6:8762. doi: 10.1038/ ncomms 9762

Conflict of Interest Statement: The authors declare that the research was conducted in the absence of any commercial or financial relationships that could be construed as a potential conflict of interest.

Copyright (c) 2018 Evrard, Kienlen-Campard, Coevoet, Opsomer, Tasiaux, Melnyk, Octave, Buée, Sergeant and Vingtdeux. This is an open-access article distributed under the terms of the Creative Commons Attribution License (CC BY). The use, distribution or reproduction in other forums is permitted, provided the original author(s) and the copyright owner(s) are credited and that the original publication in this journal is cited, in accordance with accepted academic practice. No use, distribution or reproduction is permitted which does not comply with these terms. 